\title{
Journal of Hepatology and

\section{An Evaluation of the Integrated Pulmonary Index (IPI) for the Detection of Respiratory Events in Propofol Sedated Patients Undergoing Upper Gastrointestinal Endoscopy}

\author{
Vaessen HHB $^{1^{*}}$, Knape $\mathrm{JTA}^{2}$ \\ ${ }^{1}$ Department of Anaesthesiology, Intensive Care and Emergency Medicine, University Medical Centre Utrecht, Heidelberglaan, The Netherlands \\ ${ }^{2}$ Division of Anaesthesiology, Intensive Care and Emergency Medicine, University Medical Centre Utrecht, Heidelberglaan, The Netherlands \\ "Corresponding author: H.H.B. (Paul) Vaessen, Department of Anaesthesiology, Intensive Care and Emergency Medicine, University Medical Centre Utrecht, \\ Heidelberglaan 100, The Netherlands, Tel: +31 88 7559619; E-mail: H.H.B.Vaessen@umcutrecht.nl
}

Received date: April 09, 2016; Accepted date: June 06, 2016; Published date: June 13, 2016

Copyright: (c) 2016 Vaessen HHB, et al. This is an open-access article distributed under the terms of the Creative Commons Attribution License, which permits unrestricted use, distribution, and reproduction in any medium, provided the original author and source are credited.

\begin{abstract}
Background: Monitoring of patients respiratory and ventilatory status during moderate-to-deep sedation in upper gastrointestinal $(\mathrm{Gl})$ endoscopic procedures may enable early recognition of altered respiratory patterns with potential danger for vital functions. The current standards of care for monitoring the ventilatory status during sedation are pulse oximetry and visual inspection of the breathing pattern. $\mathrm{EtCO}_{2}$ monitoring is not routinely used. The Integrated Pulmonary Index (IPI) monitor is developed to detect specific patient's respiratory depression and changes status during sedation, by measuring the $\mathrm{EtCO}_{2}$, respiratory rate, $\mathrm{SpO}_{2}$ and pulse rate, displayed on a monitor. This monitor might provide an indication of the patient's overall ventilator status. The aim of this study was to explore the validity of the IPI index during PSA procedures and its application during upper $\mathrm{Gl}$ endoscopy treatments, compared with our traditional current standards of monitoring care.
\end{abstract}

Methods: Twenty patients, scheduled for upper GI endoscopy procedures gave their informed consent. All patients were moderately to deeply sedate by trained sedation practitioners. Aside from standard monitoring, additionally the IPI was continuously measured, on a capnostream monitor. All data were analyzed and compared with the clinical status of the patient.

Results: All patients were moderate-to-deep sedated for upper $\mathrm{Gl}$ endoscopy procedures. The mean age of the patients was 56 years. In 15/100 measure points, the IPI values (lower than 7) were not in agreement with the actual clinical state of the patient. The most common discrepancies, $9 / 100$, were associated with an overshoot of the $\mathrm{EtCO}_{2}$ value, due to leakage of $\mathrm{CO}_{2}$, insufflated through the endoscope.

Conclusion: The IPI value as an early warning monitor of the ventilation in moderate-to-deep sedation procedures remains unclear and deserves further study. Its use in upper endoscopic gastrointestinal procedures where $\mathrm{CO}_{2}$ insufflation is used by the endoscopist cannot be recommended.

Keywords: Procedural sedation and analgesia; Respiration and ventilation; Integrated pulmonary Index; Patient safety; Upper GI endoscopy

\section{Introduction}

Upper gastrointestinal (GI) endoscopic procedures are standard diagnostic tools for investigation and surveillance of diseases of the gastrointestinal tract. These endoscopic procedures are often uncomfortable for the patient. To relieve this discomfort, the use of sedative and analgesic drugs, is necessary during the procedure.

Over-sedation may lead to respiratory depression while undersedation may cause discomfort for the patient [1]. Therefore, monitoring of vital functions and of the clinical effect of the sedation are essential requirements during these procedures. Guidelines $[2,3]$ recommend continuous monitoring of the circulation, of respiratory function and ventilation during Procedural Sedation and Analgesia (PSA) procedures.
Monitoring of vital signs, which could recognize and detect early changes, which might deteriorate patient's respiratory function during sedation, is necessary. Pulse oximetry monitoring only provides information on oxygenation but gives no indication on the effectiveness of the ventilation [4].

Nowadays usually, end-tidal $\mathrm{CO}_{2}\left(\mathrm{EtCO}_{2}\right)$, Respiration Rate (RR), arterial oxygen saturation $\left(\mathrm{SpO}_{2}\right)$ and Pulse Rate (PR) are more or less standard during sedation procedures [5,6]. However, early indications of a potentially dangerous change in the ventilatory status may not always be shown by any of these parameters.

The validated [7] Integrated Pulmonary Index (IPI), a numerical value, based on an algorithm, integrates 4 parameters: $\mathrm{EtCO}_{2}, \mathrm{RR}$, $\mathrm{SpO}_{2}$ and $\mathrm{PR}$, in the form of a single index value ranging from 1 to 10 (Table 1) and displayed on a monitor.

This IPI could potentially recognize changes in patient's respiratory status during PSA early enough to allow an intervention by the sedation practitioner. 
Citation: Vaessen HHB, Knape JTA (2016) An Evaluation of the Integrated Pulmonary Index (IPI) for the Detection of Respiratory Events in Propofol Sedated Patients Undergoing Upper Gastrointestinal Endoscopy. J Hepatol Gastroint Dis 2: 130. doi: $10.4172 / 2475-3181.1000130$

Page 2 of 6

\begin{tabular}{|l|l|l|}
\hline IPI Index Range & Group & Patients Status \\
\hline $7-8-9-10$ & High & Normal range \\
\hline $4-5-6$ & Medium & $\begin{array}{l}\text { Indicating that patient required } \\
\text { attention }\end{array}$ \\
\hline $1-2-3$ & Low & Requires Immediate intervention \\
\hline
\end{tabular}

IPI: Integrated Pulmonary Index

Table 1: The meaning of the IPI monitors readings.

Berkenstadt [8] used the IPI tool during colonoscopy and his results demonstrated a limited agreement between respiratory physiological parameters and the IPI. Following the example of his study, our aim was to investigate if an integrated IPI score could early recognize changes in the overall ventilatory status at ASA 1 and 2 patients [9] during upper GI endoscopy. Could this monitor reliably replace the traditional ventilatory monitoring during sedation using observation of the respiration, $\mathrm{SpO}_{2}$, and $\mathrm{EtCO}_{2}$, next to the ECG and pulse rate monitoring for safe moderate-to-deep sedation during upper GI endoscopic procedures? Therefore the IPI measurements were compared with a real time $\mathrm{SpO}_{2}, \mathrm{EtCO}_{2}, \mathrm{PR}$, and $\mathrm{RR}$ monitor and in addition the NIBP and the Observer Assessment of Alertness/Sedation $(\mathrm{OAA} / \mathrm{S})$ score were measured in an observational pilot study with 20 patients.

\section{Materials and Methods}

\section{Study population and design}

Twenty patients were scheduled in this study for an upper GI endoscopy procedure with moderate-to-deep sedation between August 2014 and November 2014. Moderate-to-deep sedation was defined according to the Continuum of Depth of Sedation [10]. All patients underwent a medical pre-assessment in accordance with the hospital sedation screening protocol and following an informed consent for the propofol based sedation, the use of IPI measurements, and the upper GI endoscopic procedures, the Endoscopic Ultrasound Esophagogastroduodenoscopy (EUS) or the Endoscopic Retrograde Cholangio Pancreatography (ERCP). Patient variables were obtained including age, sex, body mass index (BMI) and the American Society of Anesthesiology classification (ASA) status. Exclusion criteria were: age $<18$ years, ASA physical-status class $>2$, allergy against soy, eggs, and non-fasting patient. Before the GI procedure, an intravenous (IV) infusion was initiated for fluid administration. Procedural sedation and anesthesia started with the IV administration of propofol (Lipuro $10 \mathrm{mg} / \mathrm{mL}$, B. Braun) $5 \mathrm{mg} / \mathrm{kg} / \mathrm{hr}$ via infusion pump (Alaris Medical UK) and $200 \mu \mathrm{g}$ of alfentanil (Janssen-Cilag) as a bolus. Additional intravenous boluses of 10 or $20 \mathrm{mg}$ of propofol were titrated until the desired level of moderate-to-deep sedation (OAA/S sedation score of 4 or 3) was achieved, to allow the gastroenterologist to perform his upper GI endoscopy procedure. Therefore, a maximum of 4 litres $\mathrm{CO}_{2} /$ minute was insufflate continuously through the endoscope for expansion of the oesophagus, stomach, and the duodenum allowing the endoscope to be passed through these areas. Our goal was to maintain a sedation level between moderate (patient responds to verbal or tactile stimulus) and deep (patient not aroused easily but responds to painful stimuli).

\section{Monitoring}

The vital signs of all patients were continuously observed and monitored (Qube Compact Monitor; Spacelabs Healthcare, Snoqualmie, Washington, USA), and all data were recorded every 5 minutes with AnStat, an anaesthesia information management system.

Heart activity was monitored with a three-lead ECG, and the arterial oxygen saturation with a pulse oximetry. NIBP measurements were taken at 5-minute intervals, and capnography readings (Smart CapnoLine Plus; Oridion Capnography, Needham, Massachusetts, USA) were continuously recorded. An additional monitor, (Capnostream 20, Oridion Medical 1987 Ltd., Jerusalem-Israel) was installed to calculate the Integrated Pulmonary Index (IPI) rate (by using a Microstream Smart BiteBloc - Oridion Capnography Inc., Needham, MA and a $\mathrm{SpO}_{2}$ sensor). This monitor calculated the ventilatory status by measuring the $\mathrm{EtCO}_{2}, \mathrm{RR}, \mathrm{SpO}_{2}$ and $\mathrm{PR}$. Supplemental oxygen $(2 \mathrm{l} / \mathrm{min})$ was administered routinely by a nasal prong.

The IPI scores were divided to 3 groups: high IPI (score level 7-10) group indicating that the patient was in a normal range, medium IPI (score level 4-6) group indicating that the patient required attention and low IPI (score level 1-3) group indicating that the patient required immediate intervention. To assess the effectiveness of the IPI, all events with an IPI values $<7$ were identified, counted, and evaluated when it occurred for longer than one minute. These patients IPI value were compared with the traditional vital signs monitoring. The events were classified when a patient "required attention" or "required intervention" and when "no intervention "was recommended. "Required attention" events were defined as the $\mathrm{SpO}_{2}$ was $<92 \%$ and $>88 \%$ and/or RR $\leq 8$ and/or a $20 \%$ change in $\mathrm{EtCO}_{2}$ from the baseline value for more than one minute. "Required intervention" events were defined when the $\mathrm{SpO}_{2} \leq 88 \%$ and/or loss of the $\mathrm{EtCO}_{2}$ waveform for more than one minute. Procedural variables included the IPI rate, the OAA/S score [11] (Table 2) the doses of medications. A person who was not involved in the procedure registered the vital functions, $\mathrm{SpO}_{2}$, $\mathrm{EtCO}_{2}, \mathrm{PR}$, and RR. The OAA/S sedation depth score was used to measure the level of alertness of the patients who are sedated [12] and recorded every 5 minutes throughout the procedure [13]. Data on each procedure were recorded for detailed evaluation and interpretation. These data were analyzed at 5 different moments: start of sedation (I), start of endoscopy (II), 15 minutes after start of the endoscopy (III), 30 minutes after the start of endoscopy (IV) and the end of the endoscopy (V).

\begin{tabular}{|l|l|}
\hline Score Level & Observation \\
\hline 5 & Awake and responds reality to name spoken in normal tone \\
\hline 4 & Lethargic responses to name in normal tone \\
\hline 3 & Responds only after name is called loudly and/or repeatedly \\
\hline 2 & Responds only after name is called loudly and mild shaking \\
\hline 1 & Does not respond to mild pounding or shaking \\
\hline \multicolumn{2}{|l|}{ OAAS: Observers Assessment of Alertness Sedation scale } \\
\hline
\end{tabular}

Table 2: Observers Assessment of Alertness Sedation scale (OAAS). 
Citation: Vaessen HHB, Knape JTA (2016) An Evaluation of the Integrated Pulmonary Index (IPI) for the Detection of Respiratory Events in Propofol Sedated Patients Undergoing Upper Gastrointestinal Endoscopy. J Hepatol Gastroint Dis 2: 130. doi: $10.4172 / 2475-3181.1000130$

Page 3 of 6

\section{Statistical analysis}

Statistical analysis was performed using SPSS version 21 software (SPSS INC, Chicago, IL). The incidence of each IPI value (low, medium and high) between the specified sedation moments was compared with the parameters $\mathrm{SpO}_{2}, \mathrm{EtCO}_{2}, \mathrm{RR}$ and $\mathrm{PR}$ and analysed by using the descriptive statistics tool.

\section{Results}

This observational pilot study evaluated twenty patients (mean age 56; age group: 30-79, SD: 13.042 years) receiving PSA (propofol and alfentanil) for GI endoscopy procedures.
Eight patients underwent a EUS procedure and twelve patients an ERCP treatment.

All patients were categorized according to the ASA classification system as ASA 2.

Descriptive statistics of IPI (low, medium and high) values and corresponding physiological parameters $\left(\mathrm{EtCO}_{2}, \mathrm{RR}, \mathrm{SpO}_{2}, \mathrm{PR}\right.$ and $\mathrm{OAA} / \mathrm{S}$,) are compared and presented in Table 3.

\begin{tabular}{|c|c|c|c|c|c|c|c|c|c|c|c|c|c|c|c|c|}
\hline $\begin{array}{l}\text { Measure } \\
\text { moments }\end{array}$ & $\begin{array}{l}\text { Paramete } \\
\text { rs }\end{array}$ & $\mathbf{N}$ & $\begin{array}{l}\text { Minimu } \\
\mathrm{m}\end{array}$ & $\begin{array}{l}\text { Maximu } \\
\mathrm{m}\end{array}$ & Mean & $\begin{array}{l}\text { Std. } \\
\text { Deviatio } \\
\mathrm{n}\end{array}$ & $\mathbf{N}$ & $\begin{array}{l}\text { Minimu } \\
\text { m }\end{array}$ & $\begin{array}{l}\text { Maximu } \\
\mathrm{m}\end{array}$ & Mean & $\begin{array}{l}\text { Std. } \\
\text { Deviatio } \\
\mathrm{n}\end{array}$ & $\mathbf{N}$ & $\begin{array}{l}\text { Minimu } \\
\mathrm{m}\end{array}$ & $\begin{array}{l}\text { Maximu } \\
\mathrm{m}\end{array}$ & Mean & $\begin{array}{l}\text { Std. } \\
\text { Deviatio } \\
\text { n }\end{array}$ \\
\hline \multirow{6}{*}{$\begin{array}{l}\text { (I) Start } \\
\text { sedation }\end{array}$} & $\mathrm{SpO}_{2}$ & & & & & & & & & & & 20 & 93 & 100 & 97,7 & 1,976 \\
\hline & $\mathrm{EtCO}_{2}$ & & & & & & & & & & & 20 & 3,6 & 6,2 & 4,68 & 0,703 \\
\hline & $\begin{array}{l}\text { Heart } \\
\text { Rate }\end{array}$ & & & & & & & & & & & 20 & 48 & 104 & 81,5 & 16,916 \\
\hline & $\begin{array}{l}\text { Respiratio } \\
\mathrm{n} \text { rate }\end{array}$ & & & & & & & & & & & 20 & 8 & 28 & 16,3 & 5,017 \\
\hline & IPI & & & & & & & & & & & 20 & 7 & 10 & 9,1 & 1,071 \\
\hline & OAA/S & & & & & & & & & & & 20 & 5 & 5 & 5 & 0,000 \\
\hline \multirow{6}{*}{$\begin{array}{l}\text { (II) Start } \\
\text { endosco } \\
\text { py }\end{array}$} & $\mathrm{SpO}_{2}$ & & & & & & 2 & 94 & 97 & 95,5 & 2,121 & 18 & 94 & 100 & 97,72 & 1,904 \\
\hline & $\mathrm{EtCO}_{2}$ & & & & & & 2 & 4 & 4,8 & 4,4 & 0,566 & 18 & 3,2 & 5,6 & 4,48 & 0,681 \\
\hline & $\begin{array}{l}\text { Heart } \\
\text { Rate }\end{array}$ & & & & & & 2 & 70 & 100 & 85 & 21,21 & 18 & 44 & 100 & 77,44 & 14,01 \\
\hline & $\begin{array}{l}\text { Respiratio } \\
\mathrm{n} \text { rate }\end{array}$ & & & & & & 2 & 6 & 8 & 7 & 1,414 & 18 & 7 & 26 & 17,28 & 5,039 \\
\hline & IPI & & & & & & 2 & & & & 0 & 18 & 7 & 10 & 8,89 & 1132 \\
\hline & OAA/S & & & & & & 2 & 3 & 3 & 3 & 0 & 18 & 2 & & 3,11 & 0,583 \\
\hline \multirow{6}{*}{$\begin{array}{l}\text { (III) } 15 \\
\text { minutes } \\
\text { after } \\
\text { start } \\
\text { endosco } \\
\text { py }\end{array}$} & $\mathrm{SpO}_{2}$ & 1 & 99 & 99 & 99 & & 3 & 97 & 99 & 98 & 1 & 16 & 95 & 100 & 98 & 1,713 \\
\hline & $\mathrm{EtCO}_{2}$ & 1 & 9,9 & 9,9 & 9,9 & & 3 & 3,9 & 13,6 & 10,2 & 5,462 & 16 & 3,5 & 7 & 5,113 & 0,961 \\
\hline & $\begin{array}{l}\text { Heart } \\
\text { Rate }\end{array}$ & 1 & 88 & 88 & 88 & & 3 & 81 & 96 & 89 & 7,55 & 16 & 48 & 110 & 76,5 & 16,685 \\
\hline & $\begin{array}{l}\text { Respiratio } \\
\mathrm{n} \text { rate }\end{array}$ & 1 & 20 & 20 & 20 & & 3 & 8 & 26 & 14,33 & 10,116 & 16 & 11 & 32 & 18,38 & 4,924 \\
\hline & IPI & 1 & 2 & 2 & 2 & & 3 & & 6 & 5,33 & 1155 & 16 & 7 & 10 & 9,13 & 1088 \\
\hline & OAA/S & 1 & 3 & 3 & 3 & & 3 & 3 & 4 & 3,33 & 0,577 & 16 & 2 & & 2,81 & 0,655 \\
\hline \multirow{4}{*}{$\begin{array}{l}\text { (IV) } \quad 30 \\
\text { minutes } \\
\text { after } \\
\text { start } \\
\text { endosco } \\
\text { py }\end{array}$} & $\mathrm{SpO}_{2}$ & 2 & 96 & 97 & 96,5 & 0,707 & 5 & 97 & 100 & 98,8 & 1,095 & 13 & 96 & 100 & 97,92 & 1,656 \\
\hline & $\mathrm{EtCO}_{2}$ & 2 & 10,3 & 13,9 & 12,1 & 2,545 & 5 & 4 & 12,8 & 7,5 & 3,489 & 13 & 3,4 & 7 & 4,777 & 0,938 \\
\hline & $\begin{array}{l}\text { Heart } \\
\text { Rate }\end{array}$ & 2 & 86 & 95 & 90,5 & 6,364 & 5 & 67 & 92 & 82,8 & 10,33 & 13 & 55 & 108 & 76 & 14,83 \\
\hline & $\begin{array}{l}\text { Respiratio } \\
\mathrm{n} \text { rate }\end{array}$ & 2 & 5 & 16 & 10,5 & 7,778 & 5 & 8 & 27 & 18,6 & 7,127 & 13 & 14 & 31 & 19,31 & 4,571 \\
\hline
\end{tabular}


Citation: Vaessen HHB, Knape JTA (2016) An Evaluation of the Integrated Pulmonary Index (IPI) for the Detection of Respiratory Events in Propofol Sedated Patients Undergoing Upper Gastrointestinal Endoscopy. J Hepatol Gastroint Dis 2: 130. doi: $10.4172 / 2475-3181.1000130$

Page 4 of 6

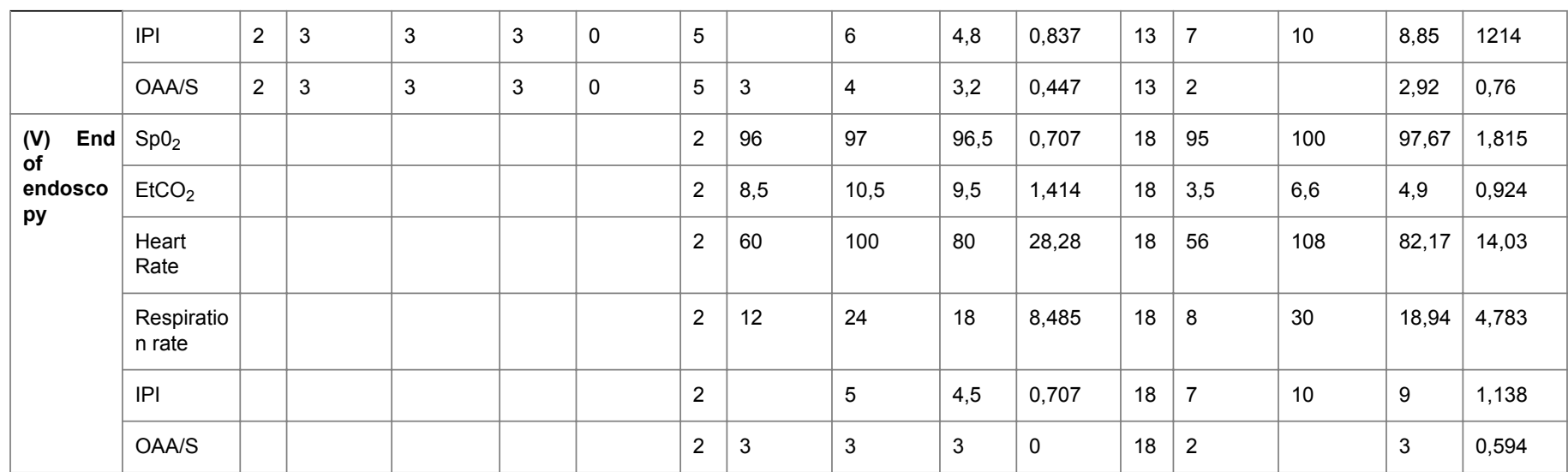

$\mathrm{SpO}_{2}$ : Pulse oximetry; $\mathrm{EtCO}_{2}$ : End-tidal carbon dioxide; IPI: Integrated Pulmonary Index; OAA/S: Observation Assessment of Alertness/Sedation; N: Number of Patients; Std. Deviation: Standard Deviation

Table 3: The distribution of physiological parameters between different IPI values.

There were no different values between the IPI groups in terms of initial $\mathrm{SpO}_{2}$ and PR. The event "no intervention "was documented for all patients when we started the sedation. Further, during the treatments, a total of 12 "required attention" events were documented. Of these 12 events, half were for an $\mathrm{EtCO}_{2}$ increase of more than $20 \%$, and in six measurement points no vital signs abnormalities were recorded. A total of 3 "required intervention" events were related to an
$\mathrm{EtCO}_{2}$ increase $\geq 20 \%$. Assuming the IPI group reflected the true ventilatory events, the IPI value was not in agreement with the observations of the condition of our patient and the OAA/S score. The overall OAA/S score during all procedures are registered in Table 4. No ventilatory and circulatory interventions were necessary during any of the procedures.

\begin{tabular}{|l|l|l|l|l|l|l|}
\hline OAAS Score & Start Sedation & Start Endoscopy & $\begin{array}{l}\mathbf{1 5} \text { Min after start } \\
\text { endoscopy }\end{array}$ & $\begin{array}{l}30 \text { min after start } \\
\text { endoscopy }\end{array}$ & $\begin{array}{l}\text { End of the } \\
\text { endoscopy }\end{array}$ & $\begin{array}{l}\text { Overall } \\
\text { score }\end{array}$ \\
\hline OAAS 5 & $100 \% \mathrm{~N}=20$ & & & & $20 \% \mathrm{~N}=20$ \\
\hline OAAS 4 & & & & & \\
\hline OAAS 3 & & $100 \% \mathrm{~N}=20$ & $55.8 \% \mathrm{~N}=11$ & $70 \% \mathrm{~N}=14$ & $55 \% \mathrm{~N}=11$ & $56 \% \mathrm{~N}=56$ \\
\hline OAAS 2 & & $45.2 \% \mathrm{~N}=9$ & $30 \% \mathrm{~N}=6$ & $45 \% \mathrm{~N}=9$ & $24 \% \mathrm{~N}=24$ \\
\hline OAAS 1 & & & & & \\
\hline
\end{tabular}

Table 4: The overall OAAS Score.

\section{Discussion}

Upper GI endoscopy treatments and procedures are often complex and time-consuming. Therefore these procedures are increasingly performed with controlled intravenous (IV) sedation to relieve the patient's pain, anxiety [14], physical discomfort, and to improve the outcome of the examination. Controlled sedation and meticulous monitoring of patients undergoing upper gastrointestinal endoscopy is in particular important because the endoscopist and the sedation practitioner share the airway, which might compromise the airway and jeopardize spontaneous ventilation easily.

In almost any GI endoscopy procedures it is mandatory to insufflate some kind of gas into the gastrointestinal tract to secure good visualization. All endoscopes used for GI endoscopy are equipped with a gas insufflation unit. Traditionally room air was used in most cases to distend tissues but the use of $\mathrm{CO}_{2}$ insufflation has become more and more popular $[15,16]$, because it was suggested to be associated with a reduction in procedure related pain experiences by the patient and decreased discomfort [17]. Compared with air insufflation, $\mathrm{CO}_{2}$ insufflation during endoscopy procedures also reduced the volume of residual gas in the digestive tract, because it diffuses rapidly into the surrounding tissues [18]. In the Fernández et al. [19] study, where the insufflation of $\mathrm{CO}_{2}$ instead of air during the endoscopy procedures was compared, the same favorable properties of $\mathrm{CO}_{2}$ were observed. Maeda et al. [20], has shown in his study that $\mathrm{CO}_{2}$ insufflation does not reduce abdominal distension and does not decrease pain scores. This in in contrast with Allen [21], who described a low prevalence of pain during his procedures when room air was inflated in gastroscopy and colonoscopy procedures, while Lord and Riss [22] considered that air could be an acceptable alternative to the more expensive $\mathrm{CO}_{2}$.

Propofol/opioid based sedation techniques are suitable to produce rapid and, when necessary, deep sedation, and its effects can be reversed within minutes. However, the line between moderate-to-deep 
Citation: Vaessen HHB, Knape JTA (2016) An Evaluation of the Integrated Pulmonary Index (IPI) for the Detection of Respiratory Events in Propofol Sedated Patients Undergoing Upper Gastrointestinal Endoscopy. J Hepatol Gastroint Dis 2: 130. doi: $10.4172 / 2475-3181.1000130$

Page 5 of 6

sedation is very narrow and the patient may easily drift into an unconscious state also in relation to rapid changes in pain sensation due to the procedure. During gastroscopy procedures which are often executed in dark or semi dark environments, observation of the ventilation may be difficult, especially when the patient is hypoventilating with minimal chest excursions. Airway obstruction or hypoventilation may be difficult to detect until hypoxia occurs as is indicated by pulse oximetry. The delayed identification of airway problems could lead to a delayed intervention causing serious morbidity [23,24]. Therefore continuous real time monitoring of the vital signs is required.

Pulse oximetry and especially capnography may provide an early warning of respiratory depression during PSA in GI endoscopy intervention, to prevent hypoxemia. However, Van Loon et al. [25] showed in their study that capnography as a monitoring mode to prevent hypoxemia during elective non-anesthesiologist administered propofol sedation does not necessarily improve patient safety. New technical developments attempt to discover a methodology to integrate ventilation and oxygenation status in one device to assist, as an early warning device, if an intervention is required for the patients' safety.

In this study we evaluated the relevance of the IPI in patients undergoing upper gastrointestinal endoscopy under sedation. The IPI integrates four parameters, $\mathrm{SpO}_{2}$, End-tidal $\mathrm{CO}_{2}$, heart rate and respiratory rate into an algorithm to produce an online numerical value between 0 and 10 . This IPI could potentially recognize changes in the patient's respiratory status at a very early moment. Garah [26] analyzed the effect of different medication dosages on the IPI during endoscopy in children even with higher ASA score patients. It is unclear, whether air or $\mathrm{CO}_{2}$ during the endoscopy was used. In his study, lower IPI levels were registered due the presence of an anesthesiologist and the use of a higher dose of medication.

Berkenstadt showed in his study evaluating the IPI for the detection of respiratory events in sedated patients undergoing colonoscopy, a limited agreement between respiratory physiological parameters and the IPI. In our study we found $12 / 100$ measure points indicating that the ventilation "required attention" and 3/100 measure points required "immediate intervention". The majority of "alarms" were associated with increases of the exhaled $\mathrm{CO}_{2}$ concentration due to the insufflation of $\mathrm{CO}_{2}$ gas by the endoscopist during upper GI endoscopy procedures. In the other "alarm" cases no association was found with data from the commonly used ventilator and circulatory parameters. Considering the inconsistency of the IPI data and based on the limited studies which have been carried out, we question whether the IPI can be developed further into a technique which will reliable inform the clinician that respiratory deterioration is at hand. A recent pilot study to test the hypothesis that the Oxygen Reserve Index would provide a clinically important warning of impending oxygen desaturation showed promising results in a selected group of patients and probably needs further exploration of its validity [27].

We conclude that the IPI has no additional value in monitoring patients under sedation for upper gastrointestinal endoscopy where $\mathrm{CO}_{2}$ is used to dilate tissues by the endoscopist. Against the background of the results of our study, we recommend further study and to repeat our study in upper gastrointestinal endoscopy where room air, as insufflating gas, is used for tissue expansion, taking into account the uncertain effects of the insufflated gas on the pain experience of the patient. Although the value of capnography for detecting airway obstruction and/or hypoventilation is still a matter of debate we recommend the combination of pulse oximetry and capnography as important monitors for evaluation of the ventilatory status of sedated patients next to personal observation of the patency of the airway, breathing movements and auscultation of the chest.

\section{Conclusion}

Although the Integrated Pulmonary Index as an integrated monitor of the ventilation has the potential to contribute to safety its use cannot be recommended in upper gastrointestinal endoscopy when $\mathrm{CO}_{2}$ is used as insufflation gas. Its value in other situations related to sedation needs to be further investigated.

\section{Acknowledgement}

The authors like to thank Oridion Capnography Inc. Jerusalem, Israel, for lending us a capnostream monitor for this study.

\section{References}

1. Schlag C, Wörner A, Wagenpfeil S, Kochs EF, Schmid RM, et al. (2013) Capnography improves detection of apnea during procedural sedation for percutaneous transhepatic cholangiodrainage. Can J Gastroenterol 27: 582-586.

2. Dumonceau JM, Riphaus A, Aparicio JR, Beilenhoff U, Knape JT, et al. (2010) European Society of Gastrointestinal Endoscopy, European Society of Gastroenterology and Endoscopy Nurses and Associates, and the European Society of Anaesthesiology Guideline: Non-anesthesiologist administration of propofol for GI endoscopy. Endoscopy 42: 960-974.

3. Lichtenstein DR, Jagannath S, Baron TH, Anderson MA, Banerjee S, et al. (2008) Sedation and anesthesia in GI endoscopy. Gastrointest Endosc 68: 815-826.

4. Galvagno SM, Kodali BS (2009) Critical monitoring issues outside the operating room. Anesthesiology Clin 27: 141-156.

5. Mehta PP, Kochhar G, Albeldawi M, Kirsh B, Rizk M, et al. (2016) Capnographic Monitoring in Routine EGD and Colonoscopy With Moderate Sedation: A Prospective, Randomized Controlled Trial. Am J Gastroenterol 111: 395-404.

6. Vaessen HH, Knape JT (2016) Considerable Variability of Procedural Sedation and Analgesia Practices for Gastrointestinal Endoscopic Procedures in Europe. Clin Endosc 49: 47-55.

7. Lightdale R, Fredette M, Atmadja M, Heard L, Jiang H. (2010) M1563: Pilot Study of the Smart Capnography Integrated Pulmonary Index $x^{\text {tw }}$ in a pediatric gastroenterology procedure unit. Gastrointest Endosc 71: AB255.

8. Berkenstadt H, Ben-Menachem E, Herman A, Dach R (2012) An evaluation of the Integrated Pulmonary Index (IPI) for the detection of respiratory events in sedated patients undergoing colonoscopy. J Clin Monit Comput 26: 177-181.

9. http://asahq.org/resources/clinical-information/asa-physical-statusclassification-system

10. http://asahq.org

11. Chernik DA, Gillings D, Laine H, Hendler J, Silver JM, et al. (1990) Validity and reliability of the observer's assessment of alertness/sedation scale: study with intravenous midazolam. J Clin Psychopharmacol 10: 244-251.

12. (2002) Practice guidelines for sedation and analgesia by nonanesthesiologists. Anesthesiology 96: 1004-1017.

13. Manyam SC, Gupta DK, Johnson KB, White JL, Pace NL, et al. (2007) When is a bispectral index of 60 too low?: Rational processed electroencephalographic targets are dependent on the sedative-opioid ratio. Anesthesiology 106: 472-483.

14. Coté CJ, Wilson S (2008) Guidelines for monitoring and management of pediatric patients during and after sedation for diagnostic and therapeutic procedures: an update. Paediatr Anaesth 18: 9-10. 
Citation: Vaessen HHB, Knape JTA (2016) An Evaluation of the Integrated Pulmonary Index (IPI) for the Detection of Respiratory Events in Propofol Sedated Patients Undergoing Upper Gastrointestinal Endoscopy. J Hepatol Gastroint Dis 2: 130. doi: $10.4172 / 2475-3181.1000130$

Page 6 of 6

15. Domagk D, Bretthauer M, Lenz P, Aabakken L, Ullerich H, et al. (2007) Carbon dioxide insufflation improves intubation depth in double-balloon enteroscopy: a randomized, controlled, double-blind trial. Endoscopy 39: 1064-1067.

16. Bretthauer M, Lynge AB, Thiis-Evensen E, Hoff G, Fausa O, et al. (2005) Carbon dioxide insufflation in colonoscopy: safe and effective in sedated patients. Endoscopy 37: 706709.

17. Dellon ES, Hawk JS, Grimm IS, Shaheen NJ (2009) The use of carbon dioxide for insufflation during GI endoscopy: a systematic review. Gastrointest Endosc 69: 843-849.

18. Shi H, Chen S, Swar G, Wang Y, Ying M (2013) Carbon dioxide insufflation during endoscopic retrograde cholangiopancreatography: a review and meta-analysis. Pancreas 42: 1093-1100.

19. Fernández-Calderón M, Muñoz-Navas MÁ, Carrascosa-Gil J, BetésIbáñez MT, de-la-Riva S, et al. (2012) Carbon dioxide vs. air insufflation in ileo-colonoscopy and in gastroscopy plus ileo-colonoscopy: a comparative study. Rev Esp Enferm Dig 104: 237-241.

20. Maeda Y, Hirasawa D, Fujita N, Obana T, Sugawara T, et al. (2013) A prospective, randomized, double-blind, controlled trial on the efficacy of carbon dioxide insufflation in gastric endoscopic submucosal dissection. Endoscopy 45: 335-341.

21. Allen P, Shaw E, Jong A, Behrens H, Skinner I (2015) Severity and duration of pain after colonoscopy and gastroscopy: a cohort study. J Clin Nurs 24: 1895-903.
22. Lord AC, Riss S (2014) Is the type of insufflation a key issue in gastrointestinal endoscopy? World J Gastroenterol 20: 2193-2199.

23. Wang CY, Ling LC, Cardosa MS, Wong AK, Wong NW (2000) Hypoxia during upper gastrointestinal endoscopy with and without sedation and the effect of pre-oxygenation on oxygen saturation. Anaesthesia 55: 654-658.

24. Reed MW, O'Leary DP, Duncan JL, Majeed AW, Wright B, et al. (1993) Effects of sedation and supplemental oxygen during upper alimentary tract endoscopy. Scand J Gastroenterol 28: 319-322.

25. van Loon $K$, van Rheineck Leyssius AT, van Zaane B, Denteneer M, Kalkman CJ(2014) Capnography During Deep Sedation with Propofol by Nonanesthesiologists: A Randomized Controlled Trial. Anesth Analg 119: 49-55

26. Garah J, Adiv OE, Rosen I, Shaoul R (2015) The value of Integrated Pulmonary Index (IPI) monitoring during endoscopies in children. J Clin Monit Comput 29: 773-778.

27. Szmuk P, Steiner JW, Olomu PN, Ploski RP, Sessler DI, et al. (2016) Oxygen Reserve Index: A Novel Noninvasive Measure of Oxygen Reserve-A Pilot Study. Anesthesiology 124: 779-784. 